\title{
Graduate student mentoring of undergraduates in the context of multi-level mentoring: Individual, departmental, and university responsibilities
}

\author{
Brent Stoffer \\ Brent Stoffer (stoffebm@mail.uc.edu), Department of Biological Sciences, University of Cincinnati, P.O. Box \\ 210006 Cincinnati, OH, USA 45221
}

As described in Weigel (2015), multi-level mentoring (in this case, the mentoring of undergraduate students by both graduate students and research advisors as opposed to mentoring from research advisors alone) is becoming increasingly common, resulting in graduate students that share the responsibilities of mentoring the undergraduate students in their research labs. While graduate students learn a variety of skills in formal settings (e.g., coursework, dissertation work, research seminars, conferences), rarely do universities teach graduate students how to mentor undergraduate students. Weigel (2015) provides graduate students, especially those in the field of ecology and evolution, the opportunity to learn about the mentoring process and think about how to implement these tools. In this commentary, I aim to expand upon some difficulties that may arise in the process, and examine the role of individuals within research labs, departments, and universities as a whole in fostering this mentor-mentee relationship.

There are differences in how to put the tools proposed by Weigel (2015) into practice, depending on the size and focus of the university or research lab. In some cases, there is a trade-off between research and teaching at the individual and university level (but see Hattie and Marsh 1996). At the least, some graduate students want to be defined by their research, others by their teaching, and others by a combination thereof (see Kendall et al. 2013). Often, the tone that is set by the university or department affects the tone of individual graduate students. If there were a research-focused tone from the university, then graduate students may be less likely to recognize the benefits of investing time and energy in the mentoring of undergraduate students. Consequently, graduate students, along with faculty at departmental and university levels, should be exposed to the benefits of graduate students mentoring undergraduate students. Ideally, this will garner new support and sustain programs that may already exist (e.g., university-wide programs pairing graduate students with undergraduate students, funding agencies sponsoring the inclusion of undergraduate students in research, coursework that brings research to undergraduate students). Because there is a clear relationship between available funding and a research faculty member's willingness to allow an undergraduate to conduct research in their lab (Eagan Jr. 2011), individuals at the departmental and university levels should continue to find creative ways to find funding to support the opportunity for undergraduate and graduate students to conduct research together. Without such funding (or the willingness within research labs to find low-cost projects appropriate for undergraduates), the benefits of graduate mentoring of undergraduate students mentioned in Weigel (2015) cannot exist.

At the interpersonal level, it is especially important to maintain proper communication among all the members involved in multi-level mentoring. Weigel (2015) provides practical advice on how to improve the means of communication between undergraduate and graduate students involved, with specific suggestions for those who conduct research in the field. It is also important, though, to think about how this one-on-one mentoring process fits into multi-level mentoring as a whole. In multi-level mentoring, there are multiple mentors involved: a single graduate student who may have the main responsibility of overseeing an undergraduate's project, other graduate students in the research lab, and a research advisor. Therefore, there are often multiple pieces of advice given to the undergraduate. Some information may be redundant and result in an enhanced 
response from the undergraduate, while other words of wisdom may conflict. Which piece of advice does the undergraduate student listen to? What is the take-home message that the undergraduate student must put into practice when designing or conducting a research project? These questions can be even further complicated, given that the most effective mentoring strategy depends on the level of experience of the undergraduate (Thiry and Laursen 2011). Thus, multi-level mentoring will only succeed if communication is maintained at all levels.

In the mentoring process, graduate students need to be reminded that both parties of interest (the undergraduate student and the graduate student) should benefit. Weigel (2015) does a great job of describing the benefits for both parties, so I will avoid re-listing them. Instead, I will point out that a cost-benefit analysis of the mentoring process would depend on the duration of stay for both parties involved. If the graduate student is leaving soon, then what is the point of investing time and energy in mentoring an undergraduate student? If the undergraduate student is only available to conduct research for six months or cannot predict how long they expect to stay in the research lab, then why should a graduate student sacrifice their time and energy by mentoring an undergraduate student? The reality is that every single one of us has at some point in time received mentoring from someone with more experience than ourselves. Whether the mentor-mentee relationship lasts six months or several years, there are benefits of this relationship. We simply have to be okay with the concept that there are benefits in academia beyond publications.

I add further suggestions on how to further improve the ability of graduate students to mentor undergraduate students and how to empirically assess these dynamics, the latter of which may be especially useful in the field of ecology and evolution. First, there needs to be more formal training on how to mentor undergraduate students. For example, the University of Wisconsin Madison developed a course (Entering Mentoring: Handelsman et al. 2005) for graduate students, postdocs, and faculty designed to parallel another course (Entering Research: Branchaw et al. 2010, Balster et al. 2010) for undergraduate students that were embarking on research for the first time in their STEM college career. The reported increase in tangible skills and confidence observed in the undergraduate students (Balster et al. 2010) can be attributed, in part, to the presence of a formal course in which mentoring practices are able to be discussed in a formal setting. I suggest that these formal settings (whether a single-day workshop, series of workshops, or an entire course) include discussions of the mentor-mentee relationship with graduate student mentors only, undergraduate mentees only, and also a mixture of mentors and mentees that are facilitated by articles such as Weigel (2015).

Second, there needs to be an improvement in the collection of data at the individual, departmental, and university levels. One of the difficulties of mentoring within ecology and evolution mentioned by Weigel (2015) is that the length of the average project can be greater in comparison to other fields. Within each lab, graduate students can assist research advisors in maintaining lab project statistics. What has been the most effective undergraduate to graduate student ratio in the lab? Is there a difference in productivity levels when undergraduate students are paired with a graduate student mentor in comparison to undergraduate students who have conducted independent projects? How long does it take to fully complete a research project in the lab? How long does an undergraduate student typically work in a research lab? Are undergraduates in the lab better off conducting projects with other undergraduates or by themselves? Can an undergraduate effectively pick up certain projects where a previous undergraduate student left off? These are the types of questions that can be answered while using the best practices in Weigel (2015). The answers to these questions have potential impact on the type of research projects a graduate student mentor may suggest for an undergraduate student, especially within ecology and evolution. Additionally, as individual research labs begin to collect this data, it will become more empirically evident whether graduate student mentors in different research labs (e.g., lab vs field studies), departments (e.g., ecology and evolution vs molecular biology), or universities (e.g., research-focused vs teaching-oriented) should adapt particular mentoring strategies described in Weigel (2015).

\section{References}

Balster, N., Pfund, C., Rediske, R., and J. Branchaw. 2010. Entering Research: A course that creates community and structure for beginning undergraduate researchers in the STEM disciplines. CBE Life Sciences Education. 9: 108-118. CrossRef

Branchaw, J., Pfund, C. and R. Rediske. 2010. Entering Research: Workshops for Students Beginning Research in Science. W.H. Freeman \& Co., New York.

Eagan Jr, M.K., Sharkness, J., Hurtado, S., Mosqueda, C.M., and M.J. Chang. 2011. Engaging undergraduates in science research: not just about faculty willingness. Research in High Education. 52: 151177. CrossRef

Handelsman, J., Pfund, C., Miller Lauffer, S., and C.M. Pribbenow. 2005. Entering Mentoring: A Seminar to 
Train a New Generation of Scientists. Madison, WI: University of Wisconsin Press.

Hattie, J. and H.W. Marsh. 1996. The relationship between research and teaching: a meta-analysis. Review of Educational Research. 66: 507-542. CrossRef

Kendall, K.D., Niemiller, M.L., Dittrick-Reed, D., Chick, L.D., Wilmoth, L., Milt, A., et al. 2013. Departments can develop teaching identities of graduate students. CBE - Life Sciences Education. 12: 316-317. CrossRef

Thiry, H. and S.L. Laursen. 2011. The role of studentadvisor interactions in apprenticing undergraduate researchers into a scientific community of practice. Journal of Science Education and Technology. 20: 771-784. CrossRef

Weigel, E.G. 2015. Modern graduate student mentors: evidenced-based best practices and special considerations for mentoring undergraduates in ecology and evolution. Ideas in Ecology and Evolution 8: 14-25. CrossRef 